\title{
Comparison of Tape Stripping with the Human Skin Blanching Assay for the Bioequivalence Assessment of Topical Clobetasol Propionate Formulations
}

\author{
Wai Ling $\mathrm{Au}^{1}$, Michael Skinner ${ }^{2}$, Isadore $\operatorname{Kanfer}^{1 *}$ \\ ${ }^{1}$ Division of Pharmaceutics, Faculty of Pharmacy, Rhodes University, Grahamstown, South Africa \\ ${ }^{2}$ Biopharmaceutics Research Institute, Rhodes University, Grahamstown, South Africa.
}

Received, October 25, 2009; Accepted, January 14, 2010; Published, January 18, 2010.

\begin{abstract}
Purpose: A draft guidance on tape stripping for assessing the bioavailability/bioequivalence of topical formulations was issued by the United States Food and Drug Administration in 1998 but has since been withdrawn. This was due to problems associated with the method and also inconsistencies and variability in the resulting data. The purpose of this study was to re-visit the tape stripping technique, incorporate refinements to reduce variability and validate the method using bioequivalence data obtained from the assessment of a topical corticosteroid cream containing $0.05 \%$ clobetasol propionate using the human skin blanching assay. Methods: A pilot tape stripping study was conducted to establish the variability of the formulations. The bioequivalence of two different commercially available clobetasol propionate cream formulations and a clobetasol propionate ointment formulation were subsequently investigated using the tape stripping method. Results: The data from the pilot tape stripping study correlated well with data from the human skin blanching assay. A subsequent pivotal tape stripping study confirmed bioequivalence between the two cream formulations whereas bio-inequivalence was demonstrated between the cream and ointment formulations. Conclusions: These studies show that the results from tape stripping concur with data from the human skin blanching assay and demonstrate the potential of a well-controlled tape stripping study as an option for the assessment of bioequivalence of topical corticosteroid formulations.
\end{abstract}

\section{INTRODUCTION}

Bioequivalence (BE) assessment of orally administered products intended for the systemic circulation is carried out by measuring plasma drug concentrations following administration of a test and reference dosage form to human subjects. However, in the case of topical preparations intended for local action, the general BE procedure used for products where the active ingredient is intended to be absorbed into the systemic circulation, cannot be used.

With the exception of topical corticosteroid preparations, BE assessment of topical products usually requires that clinical studies in patients be undertaken to compare a new formulation (test) versus an approved product (reference). However, clinical efficacy trials are time consuming and expensive (1).

Currently, the human skin blanching assay (HSBA) also known as the vasoconstriction assay (VCA) is the only acceptable BE method approved by the USA Food and Drug Administration (2) and also by many other international regulatory bodies (3-6) for the BE assessment of topical corticosteroid products. This method was originally developed by McKenzie and Stoughton (7), but it is only applicable for assessing topical corticosteroid products which produce skin blanching following application to the skin. Hence, alternative methods for the BE assessment of other topical dosage forms are needed.

Tape stripping (TS) has been investigated as a surrogate measure for bioavailability and bioequivalence assessment of topical products (8-10). It uses the concept of determining drug permeation through the stratum corneum (SC) following application to the skin of human subjects.

Corresponding Author: Isadore Kanfer, Faculty of Pharmacy, Rhodes University, South Africa, Email: i.kanfer@ru.ac.za 


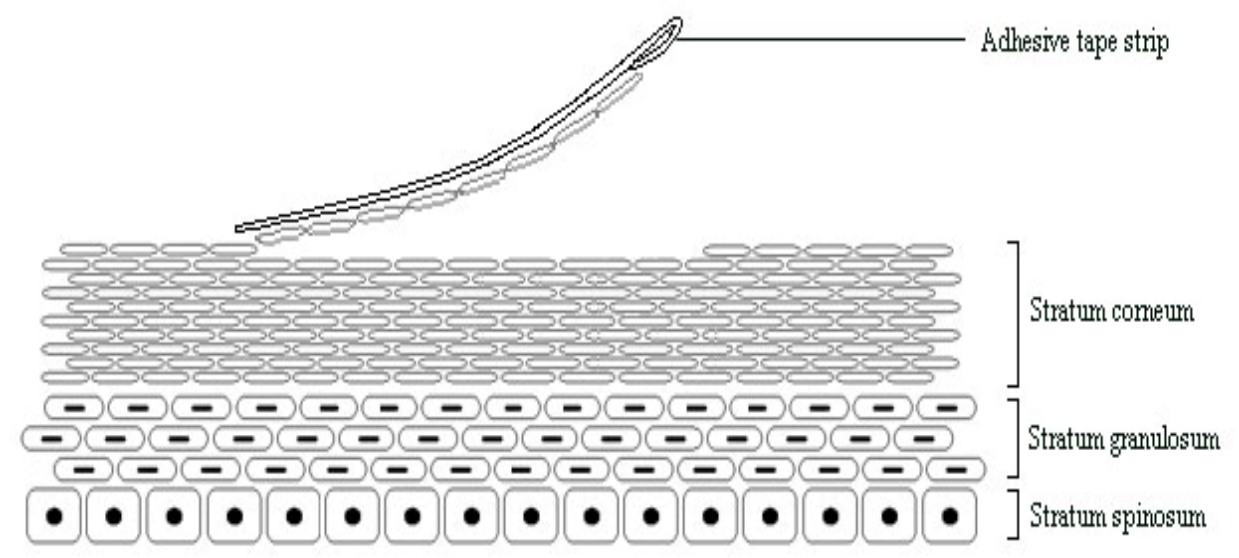

Figure 1. Removal of a layer of stratum corneum with an adhesive tape strip

This technique utilizes adhesive tape strips which consecutively remove layers of corneocytes, after which drug content is quantitatively measured in each layer of stripped skin or calculated as the cumulative amount present in all the skin strips (Figure 1). This method is considered to be relatively non-invasive due to the homeostatic nature of the skin where the SC has been shown to reform very quickly (11).

In 1998, a draft TS guidance was issued by the USA Food and Drug Administration (FDA) to assess $\mathrm{BE}$ of topical dermatological drug products. This draft was later withdrawn due to flaws found in the recommended procedures of TS. Ultimately, inter-laboratory comparative studies on the same products were found to have conflicting and opposite results (12). However, in spite of the withdrawal of the FDA's draft guidance, TS remains a promising tool and is still being investigated and optimized by a number of researchers (13-15). Previously published reports have indicated the potential of the TS technique for use in assessing the BE of topical preparations. One study showed correlations between the amount of corticosteroid in 10 tape strips versus the $90 \%$ confidence interval obtained from the HSBA of creams and ointments (16) whereas another study $(17,18)$ showed a correlation between the mean amount of corticosteroid in 10 tape strips versus the AUEC (area under the effect curve) results obtained from visual HSBA data. The above studies, however, did not use the data to assess BE.

Although the total amount of drug found in the stripped skin layers was determined in the abovementioned studies, the removed SC thickness was not taken into account. Since the total thickness of the SC removed from different sites using the same number of tape strips for each site may and usually does vary, a valid comparison between each subject and even between the tested sites within a subject cannot be made. Hence, normalization of subject skin thickness is necessary and can be undertaken using transepidermal water loss (TEWL) $(19,20)$.

The main objective of the current study was to explore the applicability of a standardized TS methodology as a viable option for BE assessment of topical dosage forms. The study design takes into account skin thickness normalization using TEWL data as well as refinements involving dosage application and duration of contact, special attention to removal of excess formulation from the skin after dosing as well as control of relative humidity and temperature of the study environment.

Initially, a pilot study was undertaken to estimate the number of subjects required for subsequent pivotal studies based on the inter-individual variability (CV\%) obtained from area under the curve of test/reference ratios. In this pilot study Dermovate ${ }^{\circledR}$ cream was used as both test and reference product. Subsequently, a pivotal study was conducted to determine whether TS was able to establish bioequivalence between 2 different topical cream formulations, a test product (Dovate ${ }^{\circledR}$ cream) and a reference product (Dermovate ${ }^{\circledR}$ cream). A further pivotal study was also undertaken between an ointment formulation (Dermovate $^{\circledR}$ ointment) and the same reference formulation previously used (Dermovate ${ }^{\circledR}$ cream). All of the 
formulations contained $0.05 \%$ clobetasol propionate $(\mathrm{CP})$.

According to the USA FDA (4) and most regulatory authorities, the declaration of bioequivalence between a test and reference product using the 2 one-sided t-test, requires that the $90 \%$ confidence interval (CI) should fall within the range of $80-125 \%$. Hence, these criteria were used to assess BE for our studies.

\section{METHODS}

\section{Materials}

CP (98\%) was purchased from Sigma-Aldrich (Atlasville, South Africa). HPLC-grade acetonitrile and methanol were purchased from Romil Ltd (Waterbeach, Cambridge, UK). The water was purified using a Milli-Q system (Millipore, Bedford, MA, USA).

\section{Formulations}

Three commercially available products each containing $0.05 \% \mathrm{~m} / \mathrm{m} \mathrm{CP}$ were utilized in the studies. Dermovate ${ }^{\circledR}$ cream (Glaxo Wellcome, Midrand, South Africa), Dovate ${ }^{\circledR}$ cream (Aspen Pharmacare Ltd, Port Elizabeth, South Africa) and Dermovate $^{\circledR}$ ointment (Sekpharma Pty Ltd, Gauteng, South Africa) were purchased from a local pharmacy in Grahamstown, South Africa.

\section{Subjects and study design}

An initial pilot TS study using 7 healthy human volunteers (2 males and 5 females, aged 23-34) who met the necessary inclusion/exclusion criteria with skin phototype II-VI (http://www. spa-medical.com/fitzpatrick_skin_typing_test.htm accessed 10 October 2008) was undertaken. The same formulation, Dermovate ${ }^{\circledR}$ cream, was used as the reference and test product. TS data were compared with data obtained from an HSBA study (21) on the same product.

The subsequent pivotal TS studies were conducted on 30 healthy human volunteers (15 males and 15 females, aged 20-36) with skin phototype of II-VI who also met the same inclusion/exclusion criteria as in the initial TS study. In these studies, the test products Dovate ${ }^{\circledR}$ cream and Dermovate ${ }^{\circledR}$ ointment were each compared against the reference product Dermovate ${ }^{\circledR}$ cream.

Room temperature $\left(22 \pm 1{ }^{\circ} \mathrm{C}\right)$ and humidity
$(45 \pm 2 \%)$ were controlled throughout the studies. Written informed consent was obtained from each volunteer before the study. The research with human subjects followed the recommended guidelines as set out in the Declaration of Helsinki (1964) and associated amendments. The study protocol was approved by the Ethical Standards Committee of Rhodes University (Grahamstown, South Africa).

\section{Application and removal scheme}

In order to ensure that the TS method had the necessary sensitivity to discriminate between $\mathrm{CP}$ topical formulations, a sigmoidal dose-response model (22) was used to determine the application exposure time or dose duration which was estimated as 2 hours.

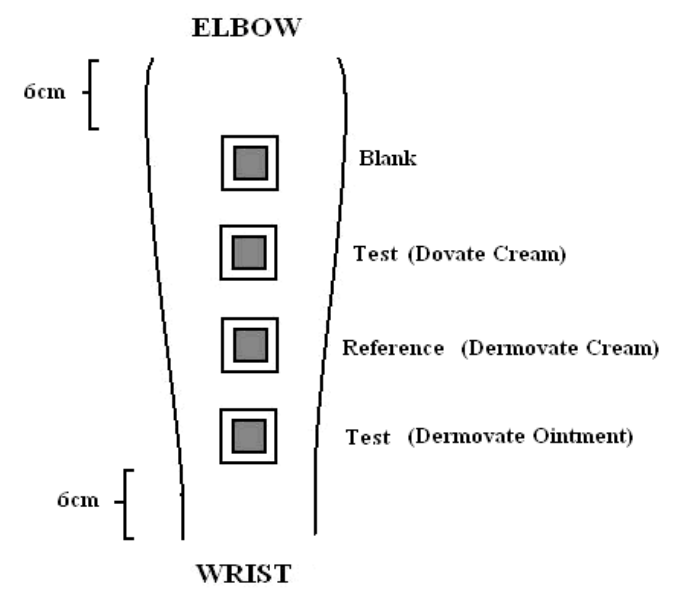

Figure 2. Scheme of application on the volar aspect of the forearm

All formulations were tested on the volar aspect of a forearm of each subject. Four $2 \times 2 \mathrm{~cm}^{2}$ square application sites were demarcated using an adhesive label (Tower, South Africa, Cape Town) on the forearms of the subjects. The book labels were cut to the appropriate size with a blade prior to the study. The sites were placed $1-2 \mathrm{~cm}$ apart and $6 \mathrm{~cm}$ away from the wrist and elbow. The treated sites were placed closer to the mid-section of the volar aspect of the forearm due to variations in percutaneous absorption from different areas on the arm (23). One site was reserved as the blank for the determination of individual SC thickness, whilst the remaining three sites were treated with the formulations as shown in Figure 2. The sites were randomized amongst the subjects to avoid bias. The 
forearm of each subject was protected after application of the relevant product, using a non-occlusive armguard to prevent the spreading of the applied topical formulation. The armguard was a clear Perspex custom-made mould to fit around the forearm with holes for ventilation and raised slightly from the skin using adhesive strips of $1 \mathrm{~cm}$ thick sponge. A weighed dose of $5.5 \mathrm{mg} / \mathrm{cm}^{2}$ was applied onto the assigned skin site with a previously calibrated Eppendorf pipette (Eppendorf Ag, Hamburg, Germany). The preparations on each demarcated skin site were carefully spread using a glass rod. The preparations were left in contact with the skin for 2 hours before removal. The excess formulation was removed by swabbing the application sites using two dry cotton buds per treated site. The skin sites were allowed to equilibrate thereafter for $5 \mathrm{~min}$ prior to TS.

\section{Individual stratum corneum thickness determination}

The blank site was used for the determination of individual SC thickness. TEWL and stripped SC weight was used for the calculation of individual SC thickness (19). A vapometer (Delfin Technologies Ltd., Kuopio, Finland) was used to take TEWL readings. TEWL measurement was taken prior to the TS procedure and immediately after each TS.

\section{TS procedure}

Fifteen individual $\sim 2.4 \times 2.4 \mathrm{~cm}^{2}$ squares of Scotch tape (Scotch Magic Tape, no. 810, $24 \mathrm{~mm} \times 50 \mathrm{~m}$, $3 \mathrm{M}$, Pymble, Australia) were utilized to sequentially tape strip the $\mathrm{SC}$ of the exposed square skin sites. The demarcation label remained on the skin during the tape stripping procedure and held intact by Scotch tape such that all skin stripping was confined to the demarcated site only. Each tape strip was weighed on a precision balance (Mettler Toledo, model AG135, Columbus, USA) prior to the study and immediately after stripping to quantitatively determine the weight of the SC removed and to minimize weight loss of the stripped skin due to possible changes in water content. TS commenced $5 \mathrm{~min}$ after the two hour dose duration when the tapes were successively placed onto the demarcated sites and stripped off with a rapid movement. The stripping process involved removing consecutive tape strips in directions changing in order of a clockwise rotation as shown in Figure 3. A pair of forceps was used to apply pressure onto the tape and was rubbed backwards and forwards 10 times to adhere each tape strip evenly to the skin site prior to stripping. Fifteen tape strips were used per site.

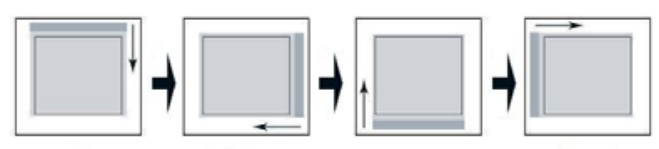

Figure 3. Direction of tape strip placement and removal.

\section{Clobetasol propionate analysis}

Each tape strip was extracted and individually analyzed, unlike previously reported studies where only some tapes were individually analyzed while some were pooled and cumulatively assayed $(18,24)$. The amount of CP in each tape strip was determined by high pressure liquid chromatography using an Alliance system comprising a 2690 Separation Module and a 2996 Photodiode Array Detector - PDA (Waters Corporation, Milford, Mass., U.S.A.). Separation was achieved using a Luna $\mathrm{C}_{8} 5 \mu \mathrm{m} 150 \times 2.0 \mathrm{~mm}$ reversed phase column (Phenomenex, Torrance, CA, USA) at a column temperature of $22 \pm 0.5^{\circ} \mathrm{C}$. A mobile phase of acetonitrile and water (46:54\%) was pumped through the system at $0.5 \mathrm{ml} / \mathrm{min}$. Twenty microlitre sample extracts were injected onto the column and CP was monitored by UV detection at a wavelength of $238 \mathrm{~nm}$.

The calibration curve was linear over the range of $0.2-2 \mu \mathrm{g} / \mathrm{ml}$ using spiked, extracted tape samples containing CP. The extraction recovery of $\mathrm{CP}$ from a tape strip was found to be in the range of $81.6 \%$ $84.7 \%$. This was determined by comparing the concentration of a pure methanolic sample of known CP concentration to an extracted spiked tape strip sample of the same concentration. The accuracy of the extracted tape strip was between $99.4-106.8 \%$ and precision $<4 \%$ RSD. Accuracy and precision were determined using blank tape stripped samples spiked with $\mathrm{CP}$ as quality control (QC) samples according the FDA guidelines (25).

\section{Extraction procedure}

Each tape strip was placed into a $1.5 \mathrm{ml}$ polypropylene microcentrifuge tube and $500 \mu \mathrm{l}$ of methanol added. The tube was vortexed for 1 minute and centrifuged at $12000 \mathrm{rpm}$ for $8 \mathrm{~min}$ (Model no. 5414, Eppendorf Ag, Hamburg, Germany) whereafter $20 \mu \mathrm{l}$ of the supernatant was 
injected onto the column.

Methanol was found to be the most suitable solvent with respect to extraction efficiency as well as the lack of interaction with tape and associated adhesive which prevented the extraction of possible interfering components from the tape strips. Furthermore, selectivity of the method was validated by extracting blank tape strips (with and without SC) and extracts of the $\mathrm{CP}$ creams and ointment, and monitoring the eluents for peak purity using PDA detection.

\section{Data Analysis}

The first tape strip was analyzed but not included in the data analysis since the first tape strip may still contain some formulation residue not removed from the skin by swabbing (15). The CP content of the first tape strip and cotton swabs was used to perform a mass balance but were not included in the data analysis as well. SC thickness $(\mathrm{H})$ was determined from the following equation (19):

\section{1/TEWL $\mathrm{T}_{\mathrm{x}}=\mathrm{H}-\mathrm{x} /$ K.D. $\Delta \mathrm{C}$}

Where TEWL $\mathrm{TE}_{\mathrm{x}}$ is the transepidermal water flux of $\mathrm{x} \mu \mathrm{m}$ of $\mathrm{SC}$ removed by a tape strip; $\mathrm{H}$ is the total SC thickness; $\mathrm{x}$ is the SC thickness removed by a tape strip i.e. partial of $\mathrm{H}$; $\mathrm{K}$ is the partition coefficient of water from the SC to viable tissue; D is the average apparent diffusivity of water in the SC of thickness $\mathrm{H}$, and $\Delta \mathrm{C}$ is the difference of water concentration across the membrane.

The SC stripping data were expressed as amount of CP per normalized fraction of SC $(x / H)$ removed based on TEWL determinations. The normalized fraction of SC allows for the comparison of data between subjects with varying $\mathrm{SC}$ thickness. The area under the curve of a plot of amount of $\mathrm{CP}$ versus normalized SC fraction was determined $\left(\mathrm{AUC}_{\text {corr }}\right)$.

For comparison purposes, the more commonly used data analysis i.e. the mean amount of drug penetrated into the skin as per area $\left(\mathrm{AUC}_{\mathrm{uncorr}}\right)$ was also determined for each formulation in the $\mathrm{BE}$ study $(13,15)$.

\section{Statistical Analysis}

Bioequivalence was determined using AUC data only following the same approach as for the
HSBA according to the guidance (2). This approach was also used in a microdialysis study to assess the $\mathrm{BE}$ of ketoprofen gels (26). The BE range was determined using untransformed AUC data (Locke's method - as described in the FDAs HSBA guidance (2)) and also log-transformed data to calculate the $90 \%$ confidence interval (CI) for the $\mathrm{AUC}_{\text {test }} / \mathrm{AUC}_{\text {ref }}$ ratios .

Interindividual variability $(\mathrm{CV} \%)$ of the log-transformed $\mathrm{AUC}_{\text {test }} / \mathrm{AUC}_{\text {ref }}$ ratios was determined using the following equation:

$$
\mathrm{CV} \%=100 *\left(\sqrt{ } \mathrm{e}^{\mathrm{MSE}}-1\right)
$$

For Locke's method, interindividual variability of the untransformed $\mathrm{AUC}_{\text {test }} / \mathrm{AUC}_{\text {ref }}$ ratios was calculated from the equation:

$$
\mathrm{CV} \%=100 * \sqrt{ }(\mathrm{MSE} / \mathrm{mean})
$$

The statistical CV\% data were computed using SAS $^{\circledR}$ statistical software (version 9.1.3, SAS Institute (PTY) Ltd., Johannesburg, South Africa)

\section{RESULTS}

\section{Pilot Study}

The permeation profile from the TS study comparing the penetration of clobetasol propionate (CP) from Dermovate ${ }^{\circledR}$ cream as both test and reference product is shown in Figure 4 where the amount of CP found in each $4 \mathrm{~cm}^{2}$ tape was plotted against the normalized skin fraction.

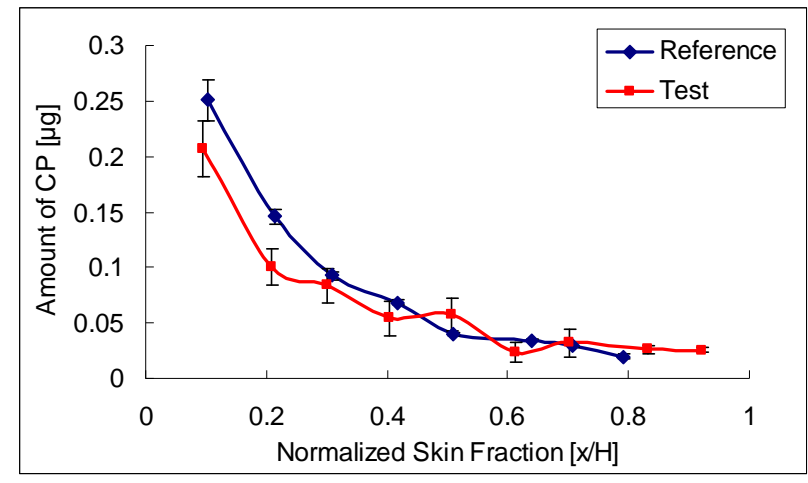

Figure 4. Mean TS profiles of the test and reference applications of Dermovate ${ }^{\circledR}$ cream. Penetration of clobetasol propionate from Dermovate ${ }^{\circledR}$ cream into the $\mathrm{SC}$ for all volunteers $(\mathrm{n}=7)$. Means with SEM. 
Table 1. Validation study - bioequivalence assessment of identical products (test -Dermovate ${ }^{\circledR}$ cream, reference - Dermovate ${ }^{\circledR}$ cream)

\begin{tabular}{lcccc}
\hline & \multicolumn{2}{c}{$\begin{array}{c}\text { Mean T/R ratio } \\
(\%)\end{array}$} & \multicolumn{2}{c}{$\begin{array}{c}\text { CI } \\
(\%)\end{array}$} \\
\cline { 2 - 5 } & Untransformed & Log-transformed & Untransformed & Log-transformed \\
\hline HSBA & 104.3 & - & $90.2-120.7$ & - \\
Chromameter & 102.9 & - & $97.9-109.2$ & - \\
Visual & 101.8 & 101.4 & $88.0-118.3$ & $87.4-117.7$ \\
\hline Tape stripping & & & & \\
\hline Pilot study & & & & \\
\hline
\end{tabular}

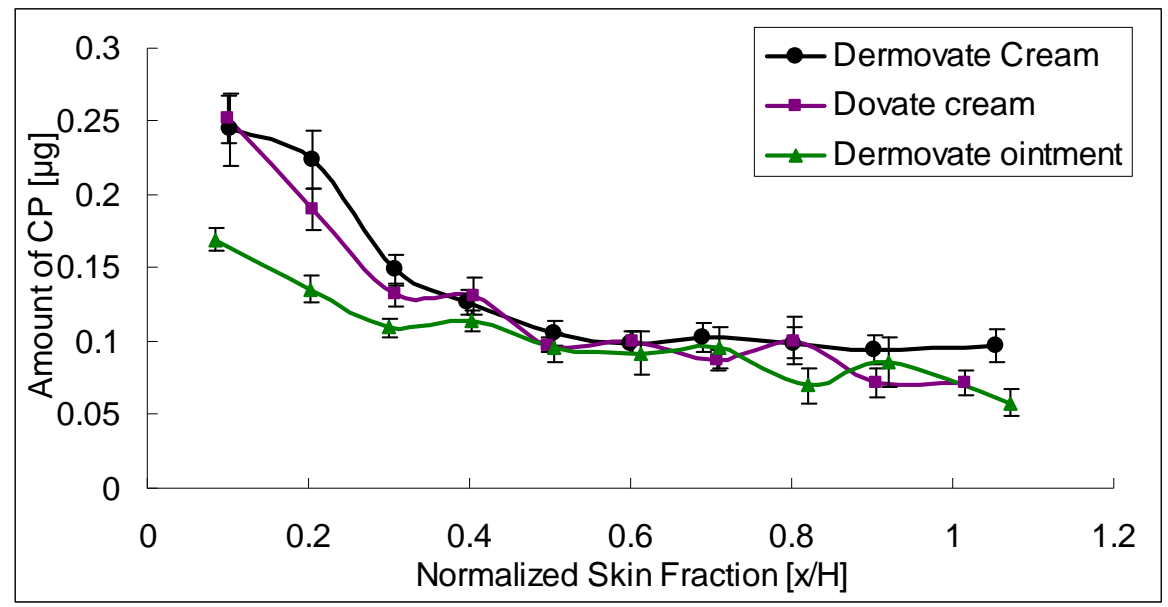

Figure 5. Mean TS profiles for the three topical products.

Table 2. Pivotal TS studies of clobetasol propionate creams and ointment products using $\mathrm{AUC}_{\text {corr }}$ data and $\mathrm{AUC}_{\text {uncorr }}$ data.

\begin{tabular}{|c|c|c|c|c|}
\hline \multirow[t]{2}{*}{ Pivotal TS Studies } & \multicolumn{2}{|c|}{ 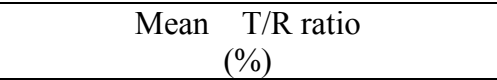 } & \multicolumn{2}{|c|}{$\begin{array}{c}90 \% \mathrm{CI} \\
(\%)\end{array}$} \\
\hline & Untransformed & Log-transformed & Untransformed & Log-transformed \\
\hline \multicolumn{5}{|l|}{ AUC $_{\text {corr }}$} \\
\hline $\begin{array}{l}\text { Dovate }{ }^{\circledR} \text { Cream vs. } \\
\text { Dermovate }{ }^{\circledR} \text { Cream }\end{array}$ & 93.8 & 92.8 & $84.7-103.6$ & $82.9-103.9$ \\
\hline $\begin{array}{l}\text { Dermovate }{ }^{(B)} \text { Ointment vs. } \\
\text { Dermovate }^{(}{ }^{\circ} \text { Cream }\end{array}$ & 66.3 & 55.2 & $48.8-82.2$ & $46.1-66.1$ \\
\hline \multicolumn{5}{|l|}{ AUC $_{\text {uncorr }}$} \\
\hline $\begin{array}{l}\text { Dovate }{ }^{\circledR} \text { Cream vs. } \\
\text { Dermovate }{ }^{\circledR} \text { Cream }\end{array}$ & 93.4 & 93.6 & $86.3-101.2$ & 86.22.-101.5 \\
\hline $\begin{array}{l}\text { Dermovate }{ }^{\circledR} \text { Ointment vs. } \\
\text { Dermovate }^{(} \text {Cream }\end{array}$ & 95.9 & 96.3 & $86.8-106.1$ & $86.6-107.1$ \\
\hline
\end{tabular}

The interindividual variability $(\mathrm{CV} \%)$ values for log-transformed and untransformed $\mathrm{AUC}_{\text {test }} / \mathrm{AUC}_{\mathrm{ref}}$ ratios were found to be $14.4 \%$ and $13.9 \%$, respectively, in the pilot study which indicated that approximately 32 subjects would be required to achieve a power of $80 \%$ (27).

$\mathrm{AUC}_{\text {test }} / \mathrm{AUC}_{\text {ref }}$ ratios obtained from the abovementioned pilot study TS profiles indicated that the test and reference product showed the same outcome as that found with data previously obtained using the HSBA (Table 1)to assess identical products (21). On the basis of these data, pivotal TS studies were undertaken as described in section 2.3 using 30 subjects to provide a power of at least $80 \%$. 

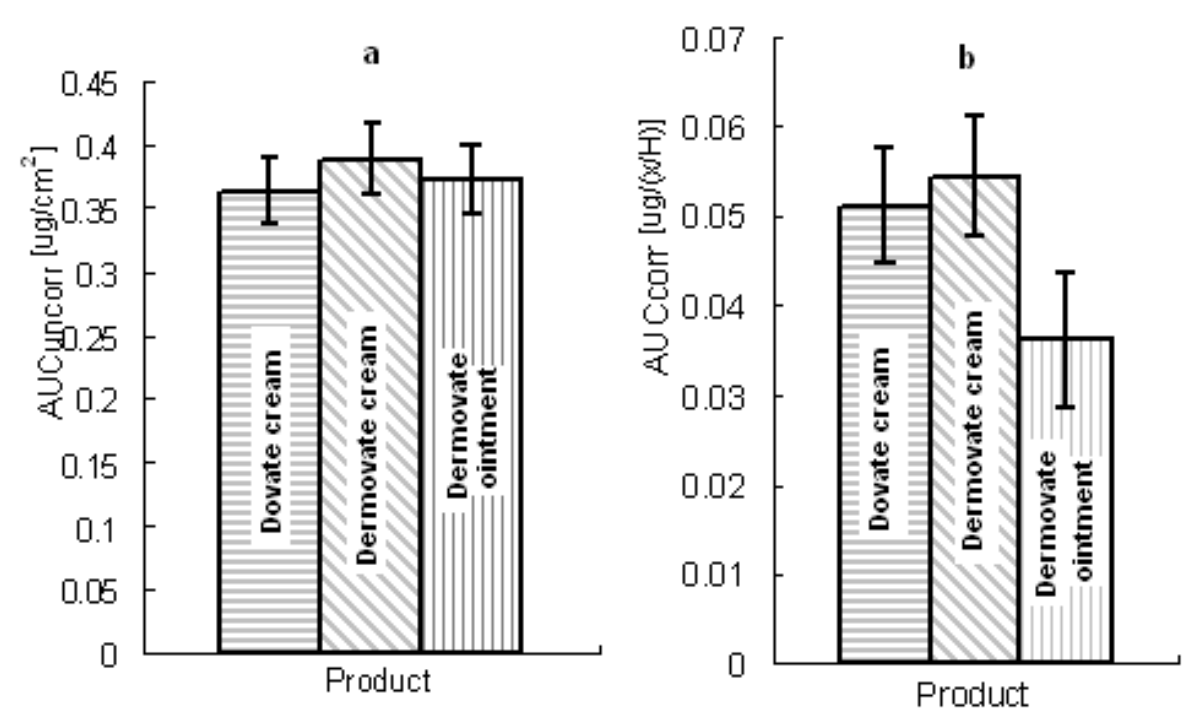

Figure 6. A comparison between the use of the $\mathrm{AUC}_{\text {uncorr }}$ and $\mathrm{AUC}_{\text {corr }}$ values of the different formulations obtained from tape stripping. (a) mean $\mathrm{AUC}_{\text {uncorr }}$ values with $\mathrm{SEM}$ and (b) mean $\mathrm{AUC}_{\text {corr }}$ values with $\mathrm{SEM}$ of Dovate ${ }^{\circledR}$ cream, Dermovate $^{\circledR}$ ointment and Dermovate $^{\circledR}$ cream for all subjects $(n=30)$.

\section{Bioequivalence Tape Stripping Study}

Penetration of clobetasol propionate from Dovate ${ }^{\circledR}$ cream (purple line), Dermovate ${ }^{\circledR}$ ointment (green line) and Dermovate ${ }^{\circledR}$ cream (black line) into the $\mathrm{SC}$ for all volunteers $(\mathrm{n}=30)$. Means with SEM.

The mean permeation profiles for the $\mathrm{CP}$ creams and ointment are depicted in Figure 5 above. The $\mathrm{AUC}_{\text {test }} / \mathrm{AUC}_{\text {ref }}$ ratios were obtained from the data used to generate these TS profiles and used to determine BE of the test product (Dovate ${ }^{\circledR}$ cream) vs. the reference product (Dermovate ${ }^{\circledR}$ cream), and Dermovate $^{\circledR}$ ointment vs. the same reference product (Dermovate ${ }^{\circledR}$ cream), all containing $0.05 \%$ CP. BE analysis of Dovate ${ }^{\circledR}$ cream vs. Dermovate ${ }^{\circledR}$ cream using both untransformed (Locke's method) and log-transformed (2 one-sided t-test) data, indicated that the products were bioequivalent where the $90 \%$ CI found were within the acceptance limits of $80-125 \%$ (Table 2). Dermovate $^{\circledR}$ ointment showed bio-inequivalence, as expected, when compared to Dermovate ${ }^{\circledR}$ cream as the reference where the $90 \%$ CI using both untransformed and log-transformed data were well outside the acceptance criteria of $80-125 \%$ as shown in Table 2.

\section{Data and Statistical Analysis}

TS data corrected for skin thickness using TEWL measurements $\left(\mathrm{AUC}_{\text {corr }}\right)$ and also the uncorrected AUC data $\left(\mathrm{AUC}_{\text {uncorr }}\right)$ were investigated and compared for the assessment of the BE between the topical products.

The $\mathrm{AUC}_{\text {uncorr }} \pm \mathrm{SEM}$ from Dovate ${ }^{\circledR}$ cream, Dermovate ${ }^{\circledR}$ ointment and Dermovate ${ }^{\circledR}$ Cream were $0.36 \pm 0.03 \mu \mathrm{g} / \mathrm{cm}^{2}, 0.37 \pm 0.03 \mu \mathrm{g} / \mathrm{cm}^{2}, 0.39 \pm$ $0.03 \mu \mathrm{g} / \mathrm{cm}^{2}$ respectively (Figure $6 \mathrm{a}$ ). The $\mathrm{AUC}_{\text {corr }}$ \pm SEM found for Dovate ${ }^{\circledR}$ cream, Dermovate ${ }^{\circledR}$ ointment and Dermovate ${ }^{\circledR}$ Cream were $0.051 \pm 0.09$ $\mu \mathrm{g} /(\mathrm{x} / \mathrm{H}), 0.036 \pm 0.07 \mu \mathrm{g} /(\mathrm{x} / \mathrm{H})$ and $0.055 \pm 0.09$ $\mu \mathrm{g} /(\mathrm{x} / \mathrm{H})$ respectively (Figure $6 \mathrm{~b})$, where $\mathrm{x} / \mathrm{H}$ is the fraction of SC removed.

Interestingly, the pivotal studies using $\mathrm{AUC}_{\text {uncorr }}$ data (log-transformed) resulted in the $90 \%$ CIs for both studies falling within the acceptance range of $80-125 \%$ for the declaration of bioequivalence for Dovate $^{\circledR}$ Cream vs. Dermovate ${ }^{\circledR}$ cream, and for Dermovate $^{\circledR}$ ointment vs. Dermovate ${ }^{\circledR}$ cream (Table 2). However, when the $\mathrm{AUC}_{\text {corr }}$ data were used, more realistic results were obtained showing that Dovate $^{\circledR}$ cream was bioequivalent to Dermovate ${ }^{\circledR}$ cream whereas Dermovate ${ }^{\circledR}$ ointment was bio-inequivalent to Dermovate ${ }^{\circledR}$ cream. 


\section{DISCUSSION}

To achieve BE between an orally administered test and reference product, the USA FDA recommends that the $90 \%$ CI should fall within the range of $80-125 \%$ (4) using log-transformed data. The specific guidance for topical dermatologic corticosteroids requires the use of untransformed data (2). In this study, two different statistical methods were used where both log-transformed and untransformed data were analysed using either AUC data corrected from TEWL measurements $\left(\mathrm{AUC}_{\text {corr }}\right)$ and also uncorrected $\left(\mathrm{AUC}_{\text {uncorr }}\right)$ values. In view of the fact that both positive and negative values can be obtained using the HSBA for topical corticosteroid products, only untransformed data can be used. However, TS data are always positive values, hence log-transformation can be used for the statistical analysis to assess BE. For this reason, both methods were used in this study to compare the outcomes.

The mean TS profiles, normalized for skin thickness, for the test and reference applications of Dermovate ${ }^{\circledR}$ cream in the pilot study showed fairly similar permeation profiles of $\mathrm{CP}$ into the SC (Figure 4). In a previously conducted pivotal HSBA study, using Dermovate ${ }^{\mathbb{B}}$ cream as both the test and reference products, $\mathrm{BE}$ between these two products was confirmed, as expected. Interestingly, statistical analysis of the pilot TS data provided the same outcomes as that of the pivotal HSBA study (Table 1).

The mean TS profiles of Dovate ${ }^{\circledR}$ and Dermovate $^{\circledR}$ creams from the pivotal study, normalized for skin thickness, were found to be similar and are depicted in Figure 5. The results from this study using log-transformed $\mathrm{AUC}_{\text {corr }}$ data showed that Dovate ${ }^{\mathbb{B}}$ cream was bioequivalent to the reference product, Dermovate ${ }^{\circledR}$ cream. Similarly, using the same $\mathrm{AUC}_{\text {corr }}$ data, application of Locke's method using untransformed data provided results comparable with the log-transformed data using the 2 one-sided t-tests (Table 2).

Although creams and ointments are not pharmaceutically equivalent and $\mathrm{BE}$ assessment between such products is generally not done, a comparison was undertaken between two different types of formulation, Dermovate ${ }^{\circledR}$ ointment (test) and Dermovate ${ }^{\circledR}$ cream (reference), to determine whether the TS method was able to discriminate differences between these formulations. Dermovate ${ }^{\circledR}$ ointment showed a lower permeation of CP into the SC than the creams ( Figure 5).

As expected, Dermovate ${ }^{\circledR}$ ointment was shown to be bio-inequivalent to Dermovate ${ }^{\circledR}$ cream using both log-transformed and untransformed $\mathrm{AUC}_{\text {corr }}$ data. This provides a useful model to show that TS was able to determine that the ointment was indeed not bioequivalent when compared with the cream (Table 2).

The use of $\mathrm{AUC}_{\text {corr }}$ data takes into account the normalized thickness of the SC into which the drug has penetrated. The thickness of intact stratum corneum on the forearm varies from $5-20 \mu \mathrm{m}$ in healthy adults. As a result, normalization of the data is necessary to allow for comparison between sites and subjects as demonstrated in a previously published report (19).

When log-transformed $\mathrm{AUC}_{\text {uncorr }}$ values were used, BE was demonstrated for Dovate ${ }^{\circledR}$ cream versus Dermovate ${ }^{\circledR}$ cream. The same result was found for these creams using Locke's method (untransformed data). However, Dermovate ${ }^{\circledR}$ ointment (test) was surprisingly shown to be bioequivalent to Dermovate ${ }^{\circledR}$ cream (reference) using both statistical methods (Table 2). Figure 6 depicts both mean $\mathrm{AUC}_{\text {uncorr }}$ (Figure 6a) and $\mathrm{AUC}_{\text {corr }}$ (Figure $6 \mathrm{~b}$ ) histograms for the different formulations. In Figure 6, using $\mathrm{AUC}_{\text {uncorr }}$, all three products appear similar, whereas using $\mathrm{AUC}_{\text {corr }}$ data, the creams appear similar but the ointment quite different. This clearly demonstrates the value of using $\mathrm{AUC}_{\text {corr }}$ values to enhance the discriminatory capability using the TS method. It should be noted, that previous studies using TS for BE assessment only used log-transformed $\mathrm{AUC}_{\text {uncorr }}$ data $(13,15)$.

To date, no statistical methods have been officially recommended for the BE assessment of topical products other than for topical corticosteroid products using the HSBA (2). In light of this, 2 different approaches to determine the CIs for the $\mathrm{AUC}_{\text {test }} / \mathrm{AUC}_{\text {ref }}$ were used, viz: the classical approach using the 2 one-sided t-test (28) with log-transformed data and Locke's method (29) which uses untransformed data. Application of either method provided similar results (Table 1 and Table 2).

\section{CONCLUSIONS}

The TS method was successfully used to assess formulations using either log-transformed or untransformed $\mathrm{AUC}_{\text {corr }}$ data. The use of $\mathrm{AUC}_{\text {corr }}$ data by normalization of the skin thickness appears to provide better discriminatory power and should be considered when using the TS method for BE assessment. Whilst the TS method has clearly been shown to be a viable alternative approach for $\mathrm{BE}$ 
assessment of CP topical products, it is important to optimize the method to control sources of variability such as, the use of an appropriate dose duration, careful removal of residual application prior to skin stripping, controlled systematic stripping orientation of each site, normalization of individual skin thickness, careful control of the dose and application of doses to demarcated skin sites, avoidance of areas on the volar aspect of the forearm where increased variability in uptake may exist such as areas near the wrist and elbows and effects of temperature and humidity of the environment where the study is being conducted.

The results of these studies illustrate the potential for TS as an alternative method for the BE assessment of topical products not intended to be absorbed into the systemic circulation.

\section{ACKNOWLEDGEMENTS}

The authors gratefully acknowledge financial support (IK) and a graduate student bursary (WLA) from the National Research Foundation, South Africa and the contribution from Charles Bon, Biostudy Solutions (Wilmington, USA), for his valuable input with the statistical analysis.

\section{REFERENCES}

1. V. P. Shah, G. L. Flynn, A. Yacobi, H. I. Maibach, C. Bon, N. M. Fleischer, T. J. Franz, S. A. Kaplan, J. Kawamoto, L. J. Lesko, J.-P. Marty, L. K. Pershing, H. Schaefer, J. A. Sequeira, S. P. Shrivastava, J. Wilkin, and R. L. Williams. Bioequivalence of topical dermatological dosage forms - methods of evaluation of bioequivalence. Pharm. Res., 15:167-171, 1998.

2. FDA. Guidance for industry: topical dermatological corticosteroids: in vivo bioequivalence. Center for Drug Evaluation, Food and Drug Administration, MD, USA 1995.

3. EMEA. Questions and answers on guideline: clinical investigations of corticosteroids intended for use on the skin. CHMP/EWP/21441/2006, European Medicines Agency, London, UK 2006.

4. FDA. Guidance of industry: bioavailability and bioequivalence studies for orally administered drug products - general considerations. Center for Drug Evaluation, Food and Drug Administration, MD, USA 2000.

5. HC. Policy issues from the drugs directorate, submissions for generic topical drugs. Health Canada, Ottawa, Canada 1990.

6. MCC. Biostudies Guideline. Medicines Control Council, South Africa 2007.

7. A. W. McKenzie and R. B. Stoughton. Method for comparing percutaneous absorption of steroids. Arch. Dermatol., 86:608-610, 1962.

8. D. Dupuis, A. Rougier, R. Roguet, and C. Lotte. The measurement of the stratum corneum reservoir: a simple method to predict the influence of vehicles on in vivo percutaneous absorption. Brit. J. Dermatol., 115:233-238, 1986.

9. C. Puglia, P. Blasi, L. Rizza, A. Schoubben, F. Bonina, C. Rossi, and M. Ricci. Lipid nanoparticles for prolonged topical delivery: An in vitro and in vivo investigation. Int. J. Pharm., 357:295-304, 2008.

10. J. C. Tsai, S. A. Chuang, M. Y. Hsu, and H. M. Sheu. Distribution of salicylic acid in human stratum corneum following topical application in vivo: a comparison of six different formulations. Int. J. Pharm., 188:145-153, 1999.

11. G. K. Menon, K. R. Feingold, and P. M. Elias. Lamellar body secretory response to barrier disruption. J. Invest. Dermatol., 98:279-289, 1992.

12. C. Herkenne, I. Alberti, A. Naik, Y. N. Kalia, F.-X. Mathy, V. Préat, and R. H. Guy. In vivo methods for the assessment of topical drug bioavailability. Pharm. Res., 25:87-103, 2008.

13. E. Benfeldt, S. H. Hansen, A. Vølund, T. Menné, and V. P. Shah. Bioequivalence of topical formulations in humans: evaluation by dermal microdialysis sampling and the dermatopharmacokinetic method. J. Invest. Dermatol., 127:170-178, 2007.

14. B. N'Dri-Stempfer, W. C. Navidi, R. H. Guy, and A. L. Bunge. Optimizing metrics for the assessment of bioequivalence between topical drug products. Pharm. Res., 25:1621-1630, 2008.

15. L. K. Pershing, J. L. Nelson, J. L. Corlett, S. P. Shrivastava, D. B. Hare, and V. P. Shah. Assessment of dermatopharmacokinetic approach in the bioequivalence determination of topical tretinoin gel products. J. Am. Acad. Dermatol., 48:740-751, 2003.

16. J. C. Tsai, C. L. Cheng, Y. F. Tsai, H. M. Sheu, and C. H. Chou. Evaluation of in vivo bioequivalence methodology for topical clobetasol 17-propionate based on pharmacodynamic modeling using chinese skin. J. Pharm. Sci., 93:207-217, 2004.

17. L. K. Pershing, L. D. Lambert, V. P. Shah, and S. Y. Lam. Variability and correlation of chromameter and tape-stripping methods with the visual skin blanching assay in quantitative assessment of topical $0.05 \%$ betamethasone dipropionate bioavailability in humans. Int. J. Pharm., 86:201-210, 1992.

18. L. K. Pershing, B. S. Silver, G. G. Krueger, V. P. Shah, and P. Skelley. Feasibility of measuring the bioavailability of topical betamethasone dipropionate in commercial formulations using drug content in skin and a skin blanching bioassay. 
Pharm. Res., 9:45-51, 1992.

19. Y. N. Kalia, I. Alberti, N. Sekkat, C. Curdy, A. Naik, and R. H. Guy. Normalization of stratum corneum barrier function and transepidermal water loss in vivo. Pharm. Res., 17:1148-1150, 2000.

20. L. M. Russell, S. Wiedersberg, and M. and Begoña Delgado-Charro. The determination of stratum corneum thickness. An alternative approach. Eur. J. Pharm. Biopharm., 69:861-870, 2008.

21. W. L. $\mathrm{Au}, \mathrm{M}$. Skinner, and I. Kanfer, Bioequivalence assessment of topical clobetasol propionate products using visual and chromametric assessment of skin blanching. J. Pharm. Pharmaceut. Sci, 11:147-153, 2008.

22. N. H. G. Holford and L. B. Sheiner. Understanding the dose-effect relationship: clinical application of pharmacokinetic-pharmacodynamic models. Clin. Pharmacokinet., 6:429-453, 1981.

23. E. Meyer, E. W. Smith, and J. M. Haigh.Sensitivity of different areas of the flexor aspect of the human forearm to corticosteroid-induced skin blanching.Brit. J. Dermatol., 127:379-381, 1992.

24. H. J. Weigmann, J. Lademann, R. von Pelchrzim, W. Sterry, T. Hagemeister, R. Molzahn, M. Schaefer, M. Lindscheid, H. Schaefer, and V. P.
Shah. Bioavailability of clobetasol propionate quantification of drug concentrations in the stratum corneum by dermatopharmacokinetics using tape stripping. Skin Pharmacol. Appl. Skin Physiol., 12:46-53, 1999.

25. FDA. Guidance for industry: bioanalytical method validation. Center for Drug Evaluation and Research, Food and Drug Administration, MD, USA, 2001.

26. R. N. O. Tettey-Amlalo, I. Kanfer, M. F. Skinner, E. Benfeldt, and R. K. Verbeeck. Application of dermal microdialysis for the evaluation of bioequivalence of a ketoprofen topical gel. Eur. J. Pharm. Sci., 36:219-225, 2009.

27. E. Diletti, D. Hauschke, and V. W. Steinijans. Sample size determination for bioequivalence assessment by means of confidence intervals. Int. J. Clin. Pharmacol. Ther. Toxic., 29:1-8, 1991.

28. D. J. Schuirmann. A comparison of the two one-sided tests procedure and the power approach for assessing the equivalence of average bioavailability. J. Pharmacokin. Biopharm., 15:657-680, 1987.

29. C. S. Locke. An exact confidence interval for unstransformed data for the ratio of two formulation means. J. Pharmacokin. Biopharm., 12:649-655, 1984. 